\title{
Proteção constitucional do meio ambiente e princípio da precaução no Brasil
}

\author{
Constitutional protection of the environment and \\ precautionary principle in Brazil
}

\author{
Eduardo Rocha Dias*
}

\section{Resumo}

Pretende-se, neste estudo, examinar como a Constituição Federal de 1988 tratou da proteção do meio ambiente, identificando as diferentes faculdades que dela decorrem e a assunção de condutas preventivas de situações que acarretam danos aos bens ambientais. Analisa-se o princípio da precaução a partir das diferentes perspectivas de tratamento jurídico de riscos e perigos, o que impõe examinar a técnica securitária e a previdenciária. Busca-se definir se da ideia de precaução é possível extrair densidade normativa para disciplinar diretamente condutas, ou se abrange tão somente o estabelecimento de deveres mais ou menos genéricos de minimizar os perigos e mesmo os riscos, desde que estes se revistam de uma mínima probabilidade, de aprofundar pesquisas científicas, de divulgar informações e de cooperação, inclusive no plano internacional. Para esse fim, o método utilizado se funda em uma análise bibliográfica e documental, assim como do tratamento conferido ao tema pela jurisprudência do Supremo Tribunal Federal. O exame de algumas decisões permitiu concluir que o Supremo Tribunal Federal nem sempre adota uma perspectiva adequada do princípio da precaução. Chegou-se ainda ao entendimento de que esse princípio leva à definição de deveres a serem cumpridos por agentes públicos e privados e que não pode obstar o exercício de atividades salvo se demonstrada a existência de riscos com base em dados científicos minimamente fundados.

Palavras-chave: Tutela constitucional. Meio ambiente. Prevenção. Princípio da Precaução.

* Doutor em Direito pela Universidade de Lisboa. Mestre em Direito pela Universidade Federal do Ceará. Professor do Programa de Pós-Graduação em Direito da Universidade de Fortaleza. Procurador Federal. Fortaleza - CE - Brasil. E-mail: eduardordias@hotmail.com. 


\section{Abstract}

This article aims to analyze how Brazil's 1988 Constitution dealt with the protection of the environment, trying to determine the different guidelines that stem from it and the adoption of preventive measures regarding damages to environmental goods. The precautionary principle is examined considering different perspectives of regulation of risks and dangers, which include insurance and social insurance techniques. It also attempts to determine whether it is possible to identify precise standards of conduct deriving from the precautionary principle or if it encompasses only general duties of reducing dangers and risks, provided the latter are likely to come into realization, of making information available to the public, of cooperation, both in domestic and in the international level, and of promoting further scientific research. In order to achieve this goal, it adopts as methodology a documental and bibliographical analysis, that includes Brazil's Supreme Court rulings that examined the matter. The study of such rulings led to the conclusion that the Court not always fully and adequately understands the precautionary principle scope. It also came to the understanding that such principle leads to the definition of duties to be observed by private and public agents and cannot impede the exercise of activities unless it is shown that there is enough scientific evidence to substantiate the existence of risks.

Keywords: Constitutional protection. Environment. Prevention. Precautionary principle.

\section{Introdução}

Algumas constituições do segundo pós-guerra incorporaram, dentre outras dimensões, a tutela de bens e direitos referidos não apenas às atuais, mas também às futuras gerações, como é o caso do meio ambiente. É o que se verifica na Constituição Portuguesa, de 1976; na Constituição Espanhola, de 1978, e em Constituições de países latinoamericanos, como a do Equador e a do Peru, ambas de 1979; a do Chile, de 1980; a da Argentina, de 1994, e a da Bolívia, de 2009. Fruto do despertar ecológico, iniciado a partir dos anos 1970, e da tomada de consciência de que a vida sobre a Terra está ameaçada, a discussão ambiental tende a se polarizar entre posições mais ecocêntricas e outras que privilegiam a pessoa e seus interesses. 
Não se pode, porém, ignorar a previsão de Cartas Constitucionais, como a brasileira, que, em seu artigo 225, consagra o direito de todos ao meio ambiente equilibrado, impondo ao poder público e à coletividade 0 dever de preservá-lo para as presentes e as futuras gerações.

Como se tem de "levar a sério" as previsões constitucionais, pretende-se examinar, neste estudo, como a Constituição Federal de 1988 protege o meio ambiente, identificando os aspectos subjetivos e objetivos de referida proteção. Também serão examinados os princípios da precaução e da prevenção, relacionados com uma atitude preventiva no tocante a riscos e perigos, almejando delimitar como podem ser empregados na tutela do meio ambiente, mas sem perder de vista que a busca da segurança é uma constante ao longo da história, o que também leva ao exame de técnicas como a securitária e a previdenciária. Também será examinado se de tais princípios decorrem condutas bem definidas, ou se levam apenas ao estabelecimento de deveres a agentes públicos e privados no tocante ao aprofundamento de estudos, à cooperação e à divulgação de informações e de minimização de riscos e perigos, desde que exista suficiente fundamentação científica, e como a jurisprudência do Supremo Tribunal Federal os tem considerado.

Para esse fim, será adotada uma metodologia fundada em uma análise bibliográfica e documental, que inclui decisões do Supremo Tribunal Federal que expressamente consideraram o princípio da precaução. Inicialmente, analisam-se as dimensões jurídicas envolvidas na tutela do meio ambiente. Em seguida, será tratado o tema do risco e como o direito o tem enfrentado. Por fim, serão examinados os princípios da prevenção e da precaução, buscando determinar seu alcance e como a jurisprudência do STF os considera.

\section{A proteção constitucional do meio ambiente: dimensões}

A proteção do meio ambiente inclui a tutela de outros bens jurídicos, como a vida, a saúde, a fauna e a flora, por exemplo, pertencentes a diversas ordens normativas. Não é incomum, portanto, que haja muitas 
vezes uma sobreposição da tutela ambiental com outros setores do ordenamento jurídico. Sob outra perspectiva, pode-se falar de uma "multifuncionalidade" ou "multidimensionalidade" no direito ao ambiente (GOMES, 1999, p. 13), o que leva a uma implicação no âmbito de outros direitos e ao reconhecimento de situações jurídicas "complexas" (MIRANDA, 2000, p. 535). A referida complexidade se manifesta, por exemplo, no duplo caráter do direito ao ambiente, simultaneamente direito subjetivo e um complexo objetivo, dotado de natureza institucional e de organização. Há, em consequência, diversos tipos de posições jurídicas dele decorrentes.

Inicialmente, como direito de defesa, impedir intervenções estatais sobre o meio ambiente. Em segundo lugar, um direito à proteção, por parte do Estado, ante a intervenções de terceiros que afetem o ambiente. Em seguida, um direito de participação em procedimentos que digam respeito ao referido bem jurídico. Ainda também um direito a exigir medidas fáticas destinadas a proteger o ambiente (ALEXY, 2001, p. 429).

Sob a primeira perspectiva, a subjetiva, muito embora não se possa recortar o "quanto" de ambiente sadio e ecologicamente equilibrado é devido a cada pessoa - o que ressalta o caráter primordialmente difuso do direito ao ambiente - ele pode manifestar-se em determinadas situações subjetivas individualizáveis. Ainda que não caiba falar de um "mínimo existencial ecológico", muitas vezes reconduzível a outros bens jurídicos, como a vida e a saúde, há determinadas situações subjetivas que não podem ser ignoradas ${ }^{1}$. Dentre elas, o direito à informação sobre o ambiente, o direito de constituir associações que busquem defendêlo, o direito a participar de decisões administrativas que a ele digam

\footnotetext{
A tentativa de identificar um "mínimo existencial ecológico" possui dificuldades semelhantes à de identificar o "núcleo essencial" dos direitos fundamentais. Se adotada uma posição relativa, tal tentativa dificilmente se afastará de uma simples aplicação dos princípios da proporcionalidade, da proibição de excesso e da metodologia da ponderação. Se adotada uma visão absoluta, é difícil não identificar tal mínimo com a dignidade da pessoa, a saúde, a integridade física ou recorrer a uma pouco frutífera busca de um núcleo irredutível de proteção, que variará de autor para autor. Nesse sentido, examinar Novais (2003, p. 779 e seguintes).
} 
respeito, dentre outras (MIRANDA, 2000, p. 540-541). É nesse ponto que se pode incluir também o direito à participação em procedimentos.

É forçoso reconhecer, no entanto, o fato de que o caráter coletivo do bem "ambiente", sua inapropriabilidade individual e a existência de um dever correlato de preservá-lo para as futuras gerações (aspecto "transgeracional") fazem predominar a dimensão objetiva (GOMES, 1999, p. 18).

Tal dimensão objetiva se manifesta em imposições de atuações fáticas concretas (como preservar e restaurar processos ecológicos essenciais e prover o manejo ecológico de espécies e ecossistemas, preservar a diversidade e a integridade do patrimônio genético do país e fiscalizar as entidades dedicadas à pesquisa e manipulação de material genético, constantes nos incisos I e II, do $\S 1^{\circ}$ do art. 225 da Constituição), imposições de legislar (presentes nos incisos III e IV do mesmo dispositivo, e que se refletem na definição de espaços a serem protegidos e na regulamentação da exigência de estudo de impacto ambiental), de fiscalizar e controlar (veja-se o inciso $\mathrm{V}$ do referido $\S 1^{\circ}$ do art. 225), de educar e conscientizar (inciso VI do $\S 1^{\circ}$ do art. 225) e de proteger a fauna e a flora (inciso VII), vedadas as práticas que coloquem em risco a função ecológica das espécies, que provoquem sua extinção ou que submetam os animais à crueldade.

O caráter precípuo de "dever fundamental" da proteção ao ambiente, imposto à sociedade e não apenas ao Estado, se evidencia no caput do art. 225 e também em seu $\S 2^{\circ}$. São os deveres fundamentais posições jurídicas ancoradas, expressa ou implicitamente, na Constituição, não necessariamente simétricas ou sinalagmáticas em relação a direitos, podendo ser autônomas ou correlatas em relação a eles, que impõem tarefas positivas ou abstenções aos indivíduos (NABAIS, 1998, p. 35). Lembre-se do dever de pagar impostos, do dever de votar, do dever de prestar serviço militar, do dever de evitar danos à saúde dos demais membros da coletividade, dentre outros.

Os deveres fundamentais não prescindem da mediação do legislador, até em face da exigência de que a liberdade deve ser 
limitada nos termos da lei, e marcam uma compreensão adequada do relacionamento entre o indivíduo e a coletividade, superando uma visão individualista e atomística do sistema de direitos fundamentais e impondo a consideração de que há exigências de solidariedade a vincular mutuamente as pessoas. Não se trata, por outro lado, de uma tentativa de funcionalizar a liberdade ou de vincular os direitos a concepções autoritárias. Os deveres se fundamentam na liberdade, na dignidade da pessoa e na igualdade (CANOTILHO, 2003, p. 531532). Essa dimensão de solidariedade, ínsita à categoria dos direitos fundamentais, se harmoniza perfeitamente com a ideia de proteção ao meio ambiente, dados os vínculos intergeracionais que pressupõe.

A ênfase dada aos direitos fundamentais, em detrimento dos deveres fundamentais, pelo menos desde a Revolução Francesa e, especialmente, no texto das constituições do segundo pós-guerra, encontra-se, conscientemente ou não, imbuída do intuito retórico de romper com o passado, com o autoritarismo, e de estabelecer uma nova ordem axiológica ${ }^{2}$ em que a tensão entre o poder e o direito seja resolvida em favor das liberdades ${ }^{3}$. Superado, porém, o momento de afirmação de novas ordens jurídicas, é possível tratar com maior isenção

2 Como lembra Bobbio (1992, p. 85), também quando a Assembleia Nacional francesa elaborava a Declaração dos Direitos do Homem e do Cidadão, discutiu-se se a feitura de uma Constituição deveria ou não ser precedida por uma declaração de direitos e se esta última somente não seria útil se acompanhada por uma declaração de deveres. O interessante debate então travado é sumariado por Rials (1988, p. 162 e seguintes). A referência aos deveres, por um lado, parece ter sido defendida por constituintes mais conservadores e apegados sobretudo a ideias religiosas. Rials (1988, p. 163) transcreve a intervenção do abade Grégoire, para quem "les droits et les devoirs sont corrélatifs; ils sont en parallèle; l'on ne peut parler des uns sans parler des autres". E que "Il est principalement essentiel de faire une déclaration des devoirs pour retenir les hommes dans les limites de leurs droits". Segundo a concepção jusnaturalista, oriunda de Pufendorf e sumariada na Encyclopédie, os deveres se classificariam em deveres em relação a Deus, em relação à própria pessoa e em relação aos outros. A ideia de respeito, fidelidade e obediência aos governantes era também enfatizada. O desejo de romper com tal tradição e de proceder a uma completa reconstrução da sociedade foi o que talvez levou à rejeição de um lista explícita de deveres. Por outro lado, a Declaração não ignorou a existência de deveres, como se verifica em seu Preâmbulo (a lembrança aos membros do corpo social de seus direitos e deveres) e em seus artigos 4 (limites ao exercício dos direitos naturais de cada um), 7 (dever de obediência dos cidadãos convocados ou detidos em virtude de lei) e 13 (contribuição comum para manutenção da força pública e para as despesas de administração).

3 As quais necessitam frequentemente de afirmação, ante o risco permanente em que se encontram de serem ignoradas ou violadas, como lembram Enterría e Fernández (2002, p. 30-31). 
o tema dos deveres fundamentais, como o dever de proteger a saúde e o meio ambiente, que se relacionam com a dimensão de socialidade ínsita a ordens jurídicas como a brasileira. Nesse sentido, a invocação de um "direito ao ambiente", mascarando-o de direito clássico, cumpre uma função simbólica e pedagógica, sensibilizando as pessoas a se tornarem responsáveis por si próprias e solidariamente pelos outros, obtendo sua adesão ao cumprimento de deveres. Afasta-se, assim, a desconfiança que a ideia de deveres poderia suscitar, inclusive no plano internacional ${ }^{4}$.

A consideração de que prevalece uma dimensão objetiva na tutela do meio ambiente, por outro lado, tem repercussões no plano processual, já que habilita a sua efetivação por meio de instrumentos como a ação popular (artigo $5^{\circ}$, inciso LXXIII, da CF/88), tendo por legitimado qualquer cidadão, ou por meio de associações de defesa do interesse em causa. Registre-se, ainda, a previsão contida no artigo 129, inciso III, da CF/88, no sentido de legitimar o Ministério Público para o manejo de ação civil pública destinada a proteger o meio ambiente e outros interesses difusos e coletivos. A Lei $n^{\circ} 7.347 / 85$, por sua vez, em seu artigo $5^{\circ}$, ampliou a legitimidade para a propositura da ação civil pública para outros entes, inclusive associações. A imbricação estreita entre a saúde e o ambiente, no Brasil, decorre do caput do artigo 225 da CF/88, que alude à relação entre o meio ambiente ecologicamente equilibrado e a sadia qualidade de vida.

O exame do desenho traçado pelo Constituinte de 1988, no tocante à proteção do ambiente, a par de incluir visões mais tradicionais, como a da tutela da natureza como objeto, ou como conjunto de bens naturais, permite considerá-la também como fonte de deveres dirigidos

\footnotetext{
4 A propósito, examinar Gomes (2007, p. 47), que afirma: “a operatividade do 'direito' ao ambiente não se traduz na possibilidade de exigir do Estado uma qualquer prestação a titulo individual, mas antes de o levar a desempenhar a tarefa de protecção e promoção da qualidade dos bens ambientais em benefício de todos os membros da comunidade. Tal fórmula contrapõe, na realidade, uma operatividade substantiva nula a um simbolismo máximo: sem se consubstanciar num direito a uma prestação precisa, incorpora um sentido pedagógico deveras relevante, na medida em que, através de um artifício linguístico, convoca as pessoas para, responsavelmente para consigo e solidariamente para com os restantes membros da comunidade, preservarem o seu suporte existencial natural".
} 
ao Estado e à sociedade. Mas a conformação de tais deveres se dará precipuamente no nível da criação legislativa, o que ressalta o papel do legislador na concretização da "Constituição do ambiente". Tal perspectiva não significa, porém, que a ampla margem de conformação do legislador não possa ser contrastada com os ditames constitucionais. Mas se impõe que a proteção do ambiente seja compatibilizada com outros bens e direitos constitucionalmente protegidos, muitas vezes por meio de uma ponderação que permita viabilizar a efetivação de uma concordância prática entre eles. Não parece decorrer da Constituição, portanto, uma visão "ecocêntrica" extremada: o foco da tutela do ambiente é a pessoa e é a pessoa socialmente considerada, o que impõe harmonizar a tutela do meio ambiente com outros direitos fundamentais.

\section{A sociedade de riscos e o tratamento jurídico do risco}

A tutela jurídica do ambiente decorre também do reconhecimento de que as sociedades modernas são "sociedades de risco" (BECK, 1998) a exigir a adoção de condutas ou abstenções por parte do Estado e de agentes privados. A ciência e a técnica amplificam os perigos em variadas áreas da vida, como a produção de alimentos e de medicamentos, trazendo também incertezas no tocante às consequências que diferentes atividades podem provocar ao meio ambiente.

A ideia de risco é associada a um "diagnóstico epocal" (LOUREIRO, 2001, p. 811), decorrente das consequências e das limitações da tecnociência, a caracterizar as sociedades modernas. Importantes setores, como o desenvolvimento tecnológico e a ecologia, são determinados por fatores em relação aos quais não existe uma experiência suficiente (SCHMIDT-AßMANN, 1997, p. 32-33), possuindo uma dinâmica própria que ultrapassa a capacidade de decidir do Estado e de agentes privados 5 .

5 Freitas Filho (2003, p. 156) adota uma terminologia diferente, aludindo a riscos tradicionais e a riscos fabricados. Os primeiros, equivalentes à noção de perigo adotada neste trabalho, decorrem da natureza ou da tradição. Seriam estimáveis, previsíveis e passíveis de proteção mediante uma técnica atuarial. Já os riscos fabricados decorrem do progresso e do desenvolvimento humano, sobretudo em razão da ciência e da tecnologia. É mais difícil conhecê-los e submetê-los a estimativas e previsões. 
Os riscos, na atualidade, deixam de ser individuais e concretos e passam a dizer respeito a toda a sociedade e a transpor as fronteiras do Estado-Nação, como a probabilidade de um alimento geneticamente modificado ou de uma substância química provocar danos à saúde ou ao meio ambiente, ou as consequências das interações de um medicamento com outras substâncias, por exemplo.

Os riscos, diferentemente dos perigos, não podem ser apreendidos segundo uma perspectiva linear e causal, demandando uma abordagem que dê conta dos fenômenos da multi e da concausalidade, bem como que ultrapasse os limites dos Estados-Nação e se revele global. A dimensão temporal da análise dos riscos deve levar em conta, ainda, uma perspectiva de mais longo prazo, já que suas consequências, muitas vezes, não afetam apenas as atuais gerações, mas também as futuras. O risco, portanto, é um perigo eventual, mais ou menos previsível, em relação ao qual não há, ou não se conhece, uma probabilidade significativa de ocorrência de um dano ${ }^{6}$.

O risco pode ser visto também como uma condição estrutural da ação em referidas sociedades: a probabilidade de que se verifique um dano futuro que outra decisão poderia ter evitado (DI GIORGI, 1998, p. 14). A sociedade moderna é caracterizada pela grande capacidade de controlar as indeterminações, mas também de produzilas. O risco seria uma modalidade de relação com o futuro, uma forma de determinação das indeterminações segundo a diferença binária probabilidade/improbabilidade (DI GIORGI, 1998, p. 197). A alternativa em relação ao risco não seria a segurança, mas outro risco. Exemplo dessa circunstância se encontra na decisão francesa de, com base no

6 Segundo Martins (2002, p. 61-62), os riscos podem ser potenciais (ou hipotéticos) e demonstrados. Nos últimos, tem-se que se conhece a probabilidade de ocorrência ou sua magnitude, e, não obstante as medidas que podem ser adotadas para evitá-los, há sempre o risco de que venham a ocorrer. É o caso dos riscos de acidentes rodoviários ou de acidentes em centrais nucleares. O risco é conhecido, muito embora a probabilidade de ocorrência seja pequena (se fosse maior, estar-se-ia diante de um perigo). Já nos riscos potenciais, ignora-se totalmente a probabilidade de ocorrência de um dano. É o caso dos alimentos geneticamente modificados, em relação aos quais não se pode dizer se há ou não riscos para a saúde. Diferentemente dos riscos e dos perigos, merece ser lembrado o fato de que toda ação humana pressupõe uma álea, ou seja, um risco residual, em que a ocorrência de dano está praticamente excluída com fundamento nos conhecimentos disponíveis e em relação ao qual não há prevenção possível. 
princípio da precaução, suspender o programa de vacinação contra a hepatite do tipo $B$, sob o argumento de se pretender evitar os riscos de a vacina provocar a ocorrência de determinadas patologias neurológicas. Paradoxalmente, assumiu-se com a decisão referida o risco de se aumentar a incidência de hepatite ou de câncer no fígado ${ }^{7}$.

Já a perspectiva jurídica vislumbra o risco como objeto de uma disciplina normativa, o que não é novidade, se for considerado, por exemplo, o direito dos seguros. A rigor, a própria técnica securitária somente vai se desenvolver, tal como hoje é conhecida, a partir do avanço da matemática e do cálculo de probabilidades, no século XVII, por meio da Lei dos Grandes Números, evidenciada pelo suíço Jacques Bernouilli. Por meio da técnica securitária, busca-se transferir as consequências de um risco, que são assumidas por um segurador mediante o pagamento de uma remuneração, denominada prêmio. Cabe ao segurador agrupar os beneficiários segundo o grau de risco a que estão submetidos e determinar, a partir do conhecimento da probabilidade de ocorrência do sinistro, o valor do prêmio a ser pago. Tal determinação exige uma atividade profissional e organizada, e bases científicas sólidas, para evitar uma indevida apreciação do risco e um equivocado cálculo do prêmio, que, se ocorrer, pode trazer prejuízo para o segurador ou para o segurado.

Há, no entanto, antecedentes históricos do seguro que se explicam em virtude da propensão natural das espécies à própria proteção e à proteção dos filhos, que no homem se desenvolverá em um sentimento de solidariedade, construído socialmente (CORDEIRO, 2013, p. 47), manifestado em diversas formas de ajuda mútua comunitária. Surge ou evidencia-se uma preocupação com o cuidado existencial, que desembocará em esquemas mais ou menos informais de agremiações ou associações visando assegurar amparo em

\footnotetext{
Exemplo apresentado por Martins (2002, p. 69).

Também conhecida por Teorema de Bernouilli, em homenagem ao seu criador, que viveu entre 1654 e 1705. Segundo tal Teorema, conforme lembra Ribeiro (2006, p. 73), a diferença entre a probabilidade teórica e a apurada empiricamente será tanto menor quanto maiores forem a homogeneidade e o número de elementos da população sob análise.
} 
situações de necessidade, como doença ou acidentes. É a vertente das mutualidades, que se desenvolverá posteriormente nas técnicas assistencial e previdenciária e na seguridade social. Ao lado de tal vertente, manifesta-se também o cuidado em amenizar os riscos de operações de trocas de mercadorias, sobretudo transportadas por embarcações. Por meio de operações de transferência ou de assunção dos riscos das viagens, surgem antecedentes do contrato de seguro. A preocupação assistencial e a preocupação negocial, portanto, encontram-se na gênese da técnica securitária (RIBEIRO, 2006, p. 7-8), que, porém, somente iria se evidenciar, tal como se conhece atualmente, na Idade Moderna, com a expansão comercial e com as bases científicas do cálculo de probabilidades, as quais tornaram possível o exercício da atividade seguradora.

O risco, nessa perspectiva, é o pressuposto do contrato de seguro, é a possibilidade de ocorrência de um evento prejudicial ao segurado ou a seus beneficiários (RIBEIRO, 2006, p. 57-58). Por meio do contrato de seguro, transfere-se a outrem, o segurador, as consequências do risco. Nem todos os riscos, porém, são seguráveis. Em primeiro lugar, exige-se que haja como estabelecer bases racionais de avaliação e controle do risco e que haja interesse do segurador em assumir o risco (RIBEIRO, 2006, p. 61). Em seguida, que haja uma multiplicidade de agentes que tenham o interesse de ceder voluntariamente seus riscos a um segurador em vez de assumi-los internamente. Os riscos hão de ser ainda decorrentes de uma atividade lícita, pois determinados riscos podem ser considerados intoleráveis em certa sociedade (RIBEIRO, 2006, p. 62). Verifica-se, portanto, que há riscos que não são passíveis de assunção por meio da técnica securitária, quer em razão de não ser possível geri-los de forma racional, quer por não haver interesse das seguradoras, quer ainda por não haver interesse dos agentes a eles expostos em cedê-los, que, por fim, podem não ser tolerados pela sociedade ou decorrer de ilícitos.

O desenvolvimento econômico e científico acaba gerando novos riscos e nem todos são seguráveis em virtude dos fatores acima expostos. Isso pode explicar, por um lado, o surgimento de seguros 
"obrigatórios", fundados em um interesse social relevante (pense-se no seguro obrigatório de acidentes provocados por veículos automotores, no seguro em contratos de financiamento habitacional e, no passado, antes de sua assunção pelo Estado, no Brasil, no seguro de acidentes de trabalho) e na afirmação de outros mecanismos de proteção. É o caso do Fundo Garantidor de Créditos, referentes ao sistema financeiro, criado pela Resolução 2.211, de 16 de novembro de 1995, do Conselho Monetário Nacional, que cobre prejuízos decorrentes da quebra de instituições financeiras até a importância de duzentos e cinquenta mil reais por titular e por instituição financeira. Também é o caso da assunção, pelo Estado, de responsabilidade por determinados danos oriundo de riscos que dificilmente seriam assumidas por sociedades seguradoras ou passíveis de gestão pela técnica securitária. Exemplos de tais riscos são os referentes a danos nucleares, atribuídos pela Constituição à União (Art. 21, inciso XXIII, alínea d), os alusivos a atentados terroristas e atos de guerra contra aeronaves, tratados pela Lei $10.744 / 2003$, e os envolvidos pela realização, no Brasil, da Copa do Mundo de 2014 (Lei 12.663/2012).

Pode-se falar, sob outra perspectiva, de riscos tecnológicos, decorrentes da criatividade humana e do desenvolvimento da técnica, a atrair a necessidade de procedimentos de avaliação, comunicação e adaptação a novos dados resultantes das pesquisas científicas, etapas que compõem a gestão do risco (GOMES, 2014, p. 21).

Verifica-se, portanto, que o risco e a busca de segurança em relação a ele, são constantes na História. Diferentes são as respostas oferecidas, a depender das características relacionadas a cada risco. A técnica securitária pode ser perfeitamente empregada no tocante aos riscos ambientais. Não há no Brasil, porém, a obrigatoriedade de contratação de seguros. Trata-se de medida que poderia auxiliar na prevenção e reparação de danos ao meio ambiente, na medida em que seguradoras especializadas poderiam auxiliar os titulares de empreendimentos potencialmente poluidores a minimizarem os riscos e a prevenir sua ocorrência, bem como poderiam, na eventualidade de ocorrência de um sinistro, garantir a reparação dos danos. 


\section{Os princípios da prevenção e da precaução}

A imprevisibilidade, a instabilidade e a indeterminação que se manifestam em diferentes áreas, como o meio ambiente e a saúde, tornam necessário um tratamento jurídico-constitucional adequado do risco, a se manifestar, dentre outros aspectos: na definição do seu grau de aceitabilidade e no princípio da precaução ${ }^{9}$, a orientar decisões de agentes públicos e privados, o que implica uma ponderação entre os custos e as vantagens das decisões a serem adotadas; na previsão de deveres informativos e de aprofundamento de pesquisas científicas, com a finalidade de se diminuir a incerteza; e na determinação da responsabilidade por danos causados. É necessário, portanto, que o direito se adapte para dar conta do fenômeno da sociedade do risco, passando a revestir-se de maior flexibilidade e capacidade de inovação (SCHMIDT-AßMANN, 1997, p. 33).

Mas como se deve compreender o princípio da precaução? Faz-se referência a ele como integrando o texto de constituições ${ }^{10}$, de instrumentos internacionais ${ }^{11}$ e de normas comunitárias ${ }^{12}$.

Ou melhor, no princípio da prevenção "agravada" a que se refere Gomes (2005, p. 157).

10 Considerando apenas os âmbitos da saúde e do ambiente, a CF/88, em seu artigo 196, prevê a adoção de políticas que visem à "redução do risco de doença e outros agravos"; o caput do seu artigo 225 estabelece o dever da coletividade e do poder público de defender e preservar o meio ambiente para as presentes e as futuras gerações; o inciso $V$ do parágrafo primeiro do artigo 225 da referida Carta impõe ao poder público "controlar a produção, a comercialização e o emprego de técnicas, métodos e substâncias que comportem risco para a vida, a qualidade de vida e o meio ambiente". Este último dispositivo é apontado como sede constitucional do princípio da precaução no direito brasileiro, conforme Machado (2004, p. 65-66). Não parece, no entanto, decorrer de tal previsão normativa um dever de atuação nas hipóteses de incerteza científica - cerne do princípio da precaução - podendo perfeitamente a referência a medidas de controle ser interpretada como limitando-se a atitudes preventivas. Em Portugal, examinem-se os artigos $64, n^{\circ} 3$, e 66, n 2, da Constituição da República Portuguesa. Considerando o princípio da precaução como integrante do âmbito de proteção das normas constitucionais referentes ao meio ambiente, não obstante a ausência de previsão expressa nesse sentido, examinar Martins (2002, p. 74 e seguintes). A autora funda seu entendimento nas referências constantes da Carta Portuguesa a respeito da solidariedade entre gerações e da necessidade de aproveitamento racional dos recursos naturais. Em sentido contrário, afirmando que não há previsão constitucional de referido princípio e adotando uma visão cética quanto à sua existência e ao seu conteúdo, examinar Gomes (2005, p. 143 e seguintes, especialmente p. 161). A autora, de forma mais consistente, defende a ideia de que os referidos dispositivos constitucionais consagram, na verdade, a ideia de prevenção e que a solidariedade intergeracional e o aproveitamento racional de recursos naturais são princípios autônomos. Ademais, o chamado princípio da precaução é dotado de grande ambiguidade, mostrando-se pouco operativo, como será explicitado neste trabalho a seguir. 


\section{É certo que a ideia de precaução envolve a adoção (ou a proibição) de medidas interventivas ainda quando não haja certeza}

11 Surgido na Alemanha na década de setenta do Século XX, em consequência da emergência de uma maior preocupação com a Ecologia, o princípio da precaução foi reconhecido pela primeira vez no plano do Direito Internacional na Carta Mundial da Natureza, adotada pela Assembleia Geral das Nações Unidas em 1982. Posteriormente, foi acolhido pela Segunda Conferência Ministerial do Mar do Norte, em 1987. Na Convenção de Viena, de 1985, e, no Protocolo de Montreal, de 1987, referentes à proteção da camada de ozônio, também se encontram alusões ao princípio. Sua consagração como princípio geral do Direito do Ambiente decorreu da Declaração Ministerial de Bergen para o Desenvolvimento Sustentado, de 1990 e, principalmente, da Declaração do Rio sobre Meio Ambiente e Desenvolvimento, da Cúpula da Terra, no Rio de Janeiro, de 1992. Nesse sentido, examinar a Comunicação da Comissão das Comunidades Europeias relativa ao princípio da precaução, de 02 de fevereiro de 2000, e, ainda, Bohanes (2002, p. 330 e seguintes) e Martins (2002, p. 28 e seguintes). Muito embora se reconheça a integração do princípio da prevenção no Direito Internacional, nem todos afirmam o mesmo quanto ao princípio da precaução, em virtude das dificuldades de definição de seu conteúdo e da resistência da jurisprudência internacional em reconhecê-lo como um princípio jurídico autônomo. Nesse sentido, Prévost (2004, p. 41 e nota 39), Loureiro (2001, p. 875-877), Martins (2002, p. 35-37) e Gomes (2005, p. 149-151). Para a última autora citada, os documentos internacionais citados nada mais fazem do que consagrar um conjunto de medidas preventivas de grande diversidade destinadas a serem concretizadas de acordo com as condições de cada país. Mencione-se, ainda, a decisão do órgão de apelação da Organização Mundial do Comércio a respeito do embargo da Comunidade Européia à carne de animais tratados com hormônio de crescimento oriunda dos Estados Unidos e do Canadá. Considerou-se que o embargo, adotado com fundamento no princípio da precaução, acolhido no item 5.7 do Acordo a respeito da aplicação de medidas sanitárias e fitossanitárias (SPS Agreement), viola as normas da OMC, especificamente o item 5.1 do aludido acordo. Referido dispositivo exige a demonstração de risco para a saúde ou a segurança com fundamento em critérios científicos para que se possa manter a aplicação de medidas como as adotadas pela Comunidade Europeia. Na opinião do referido órgão de apelação, sem suficiente comprovação científica, não se poderia manter a proibição, a qual somente seria aceitável como medida provisória. A decisão de proibir a importação de carne de animais aos quais se ministrou hormônios fundou-se também na percepção de risco dos consumidores. O órgão de apelação da OMC, porém, considerou que tal percepção não é aceitável por não ser cientificamente provada. Há, portanto, nítida divergência acerca da compreensão do princípio da precaução adotada pela Comunidade Européia e pelo referido órgão da OMC. Posteriormente, ao decidir que as medidas de quarentena adotadas pelo Japão, no sentido de coibir a importação de maçãs dos Estados Unidos da América, com a finalidade de evitar contaminação por uma determinada praga, violavam o SPS Agreement, o Panel instalado para tal fim e, posteriormente, o órgão de apelação da OMC fixaram um entendimento mais preciso acerca do alcance do referido item 5.7. Mencionado dispositivo deve ser aplicado em situações em que há falta de suficiente comprovação científica a respeito do risco considerado, seja em razão da pequena quantidade de provas sobre novos riscos ou da circunstância de as provas acumuladas serem inconclusivas ou não confiáveis. Em ambos os casos, a insuficiência de comprovação deve ser tal que torne impossível uma avaliação do risco. O item 5.7, por outro lado, não pode ser utilizado para justificar medidas que desconsiderem os dados científicos, somente sendo aplicável em casos excepcionais em que há uma verdadeira falta de provas científicas confiáveis e relevantes, não podendo servir como brecha por onde possam passar medidas protecionistas. A respeito do tema, examinar Prévost (2004, p. 42).

12 Somente com o Ato Único Europeu, de 1986, é que foram reconhecidas competência ambientais à Comunidade Europeia. É no artigo $174, n^{\circ} 2$, do Tratado de Roma, com a redação decorrente dos Tratados de Maastricht e de Amsterdam, que se encontra a referência ao princípio da precaução. Como ressalta Gomes (2005, p. 162), de referido dispositivo não decorre qualquer vinculação para os Estados-membros, já que não há nenhuma obrigação clara, precisa e incondicional dele deduzível. Tanto isso é verdade que o Tribunal de Justiça das Comunidades Européias já entendeu que não pode haver responsabilização dos Estados-membros por supostas violações a referido princípio (caso C-379, conhecido como caso "Peralta"). O que pode ocorrer é a imposição de deveres concretos por meio de regulamentos e diretivas. 
científica, sequer quanto aos efeitos nocivos, nem quanto à relação de causalidade entre estes e uma determinada atividade.

Grassam dúvidas, porém, no tocante à definição de até onde se pode desconsiderar os dados da ciência para se defender o meio ambiente e a saúde, e ao grau exigível de prova dos danos. Tais dúvidas se refletem em instrumentos internacionais, que pouco auxiliam na definição do alcance do princípio.

Na redação em inglês do Princípio 15 da Declaração do Rio sobre Meio Ambiente e Desenvolvimento, da Cúpula da Terra, realizada no Rio de Janeiro, em 1992, tem-se que

Com o fim de proteger o meio ambiente, o princípio da precaução deverá ser amplamente observado pelos Estados, de acordo com suas capacidades. Quando houver ameaça de danos graves ou irreversíveis, a ausência de certeza científica absoluta não será utilizada como razão para o adiamento de medidas economicamente viáveis para prevenir a degradação ambiental.

Nos considerandos do preâmbulo da Convenção da Diversidade Biológica, assinada no Rio de Janeiro, em 5 de junho de 1992, lê-se: "Observando também que, quando exista sensível redução ou perda de diversidade biológica, a falta de plena certeza científica não deve ser usada como razão para postergar medidas para evitar ou minimizar essa ameaça [...]". Já na Convenção-Quadro das Nações Unidas sobre a Mudança do Clima, em seu artigo $3^{\circ}$, referente aos "Princípios", temse que

Quando surgirem ameaças de danos sérios ou irreversíveis, a falta de plena certeza científica não deve ser usada como razão para postergar essas medidas, levando em conta que as políticas e medidas adotadas para enfrentar a mudança do clima devem ser eficazes em função dos custos, de modo a assegurar benefícios mundiais ao menor custo possível.

Ora, é de se exigir "ameaça de sensível redução ou perda de diversidade biológica" ou "ameaça de danos sérios ou irreversíveis"? Será mesmo possível exigir plena certeza científica, diante do caráter 
sempre provisório de tal saber? A preocupação com o balanço custos/ benefícios integra ou não o princípio? Deve-se concluir que uma afirmação excessivamente rígida do princípio da precaução inviabilizaria por completo o progresso humano, evitando-se a adoção de novas tecnologias. Ademais, revelar-se-ia uma consequência de uma noção excessivamente "ecocêntrica" do direito ao ambiente, que pode fazer perder de vista sua íntima ligação com a promoção da vida humana. Haveria nítida perda da função legitimadora da ciência, além de consequências políticas e econômicas nefastas ${ }^{13}$.

Mostra-se mais adequado, portanto, exigir a demonstração de um risco com fundamento científico razoável. Sem exigir uma garantia de risco zero, que abrangeria até os riscos residuais, o que não é realista, e sem exigir uma probabilidade elevada de ocorrência, é necessária uma perspectiva intermediária que permita identificar e gerir os riscos com base na sua gravidade e na probabilidade de sua ocorrência. Isso implica definir quais riscos são aceitáveis e quais não o são, atendendo aos benefícios decorrentes da atividade que os produz. Diante das sérias dúvidas quanto à abrangência do princípio da precaução, mostrase mais adequado falar em princípio da prevenção "agravada" associado à ideia de proporcionalidade e de ponderação entre o que se protege e a forma de proteção (GOMES, 2005, p. 157).

Importante ainda é a adoção de deveres destinados a minimizar os perigos e mesmo os riscos, desde que estes se revistam de uma mínima probabilidade, como deveres de aprofundar as pesquisas científicas, de divulgar informações, de cooperação, inclusive no plano internacional, de promoção da participação do público nos procedimentos decisórios, de realização de procedimentos de avaliação de impacto ambiental e de risco ambiental, de estabelecimento de cláusulas de revisão das decisões de acordo com os avanços da técnica, dentre outros ${ }^{14}$.

13 Sunstein (2006) conclui que uma aplicação forte do princípio da precaução não conduz a nenhuma orientação. Ademais, deve-se também elaborar um balanço adequado dos perigos existentes, visando minimizar a possibilidade de manipulação por grupos de interesse.

14 Sobre o princípio da precaução, examinar ainda Machado (2004, p. 55 e seguintes), Leite e Ayala (2004, p. 70 e seguintes) e Martins (2002, p. 65 e seguintes). Sobre as diversas pré-compreensões ligadas à noção de ambiente, ver Canotilho (2004, p. 177 e seguintes) e Gomes (1999, p. 25 e seguintes). 
Como decorrência da maior velocidade dos progressos da ciência, da técnica e do reconhecimento dos limites de tais saberes, materializado no aumento de incertezas, a distinção entre riscos e perigos parece adequada, pois propicia aos poderes públicos estabelecer (sobretudo por via legislativa ou regulamentar) e avaliar (em especial no curso de procedimentos administrativos e jurisdicionais) as medidas adotadas ou a adotar com fundamento nos diferentes graus de probabilidade de ocorrência de certos eventos. Sendo possível afirmar que a diferença entre riscos e perigos é muito mais uma diferença de grau quanto ao nível das incertezas do que propriamente de natureza, segue-se que a distinção entre princípios da prevenção e da precaução é também uma diferença de grau. Portanto, é possível compreender a precaução como inserida no campo da prevenção (VAQUÉ; EHRING; JACQUET, 1999, p. 88). Ante as incertezas quanto ao conteúdo e alcance da primeira ideia referida, é possível e adequado falar em prevenção "agravada" ou "alargada" no tocante à definição de como se agir em face de situações de risco.

As incertezas ocasionadas no seio da "sociedade de risco" não podem, porém, justificar a paralisação do progresso, a ossificação da técnica e a desconsideração da ciência e dos direitos e valores fundamentais, como a liberdade de iniciativa econômica. Daí por que se devem afastar compreensões rígidas e maximalistas da ideia de precaução, que exigiria "risco zero" e certeza "absoluta", o que é irrealista, mas fundar as decisões quanto a agir ou não em dados científicos sérios (ainda que não unânimes) e na adoção de procedimentos em que se dê a oportunidade de manifestação a todos os possíveis interessados. Deve-se, com fundamento no princípio da proporcionalidade, definir a adequação e a necessidade das medidas a serem adotadas, ante a existência ou não de situações de urgência e a gravidade dos danos que possam decorrer para bens jurídicos, como a saúde e o meio ambiente, bem como o prazo de aplicação de referidas medidas.

Não se deve, portanto, pretender fazer do princípio da precaução uma cláusula genérica que permita obstar o desenvolvimento de qualquer atividade sem o mínimo de demonstração de existência de um risco. Em 
conclusão, examine-se a jurisprudência do Supremo Tribunal Federal, que, além de reconhecer que o princípio da precaução decorre da Carta de 1988, nem sempre se refere a ele da maneira mais adequada.

Assim, no Agravo Regimental no Agravo de Instrumento $\mathrm{n}^{\circ}$ 781.547, sendo relator o Ministro Luis Fux, se manteve decisão que havia condenado estabelecimento comercial pelo nível de ruído constatado em perícia realizada em aparelho de ar condicionado. Logo, efetuou-se uma prova de que o nível de ruído superava o mínimo permitido, o que violaria o princípio da precaução, segundo o acórdão recorrido. Ora, a prova técnica produzida constatou a violação a uma previsão normativa expressa, sobre o nível de ruído aceito, não parecendo hipótese de aplicação do princípio da precaução, que, como visto mais acima, pressupõe a existência de certo grau de incerteza científica. A referência ao princípio da precaução, portanto, não parece adequada.

Já na ADPF 101, que tinha por objeto normas proibitivas da importação, pelo Brasil, de pneus usados, o princípio da precaução foi mais adequadamente referido. No voto da relatora, Ministra Cármen Lúcia, procedeu-se à distinção entre ele e o princípio da prevenção, levando em conta o grau de certeza do dano. Aduziu-se que não se faz necessário demonstrar um risco atual, iminente e comprovado para se adotar medidas com base no princípio da precaução, mas sim riscos futuros e possíveis. Fez-se referência à sua sede constitucional, tanto no tocante ao meio ambiente quanto à saúde, mas não se avançou no tocante à definição de como seria aplicado e ao grau de certeza científica que deve ser exigido. Muito menos se fez referência à necessidade de ouvir os interessados e adotar deveres de aprofundar as pesquisas científicas, de divulgar informações, de cooperação, inclusive no plano internacional, de promoção da participação do público e outros.

Diante de tais omissões é de se questionar mesmo qual é o nível de operacionalidade do princípio e se ele decorre efetivamente do inciso V do art. 225 da Constituição. A atuação no tocante a riscos, que se prevê em aludido dispositivo, pode muito bem apontar apenas para uma atitude preventiva imposta ao poder público, a ser concretizada normativamente 
em variados níveis. Assim, a proteção dos consumidores e do meio ambiente se ampararia na visão de prevenção, e não de precaução.

\section{Conclusão}

Impõe-se considerar que, dado o caráter aberto do texto constitucional, no tocante à tutela do meio ambiente, predomina uma dimensão objetiva, já que há mais uma imposição de deveres do que propriamente uma consagração de direitos. Há, porém, determinadas dimensões subjetivas que se podem destacar da Constituição, como o direito à informação sobre o ambiente, o direito de constituir associações que busquem defendê-lo e o direito a participar de decisões administrativas que a ele digam respeito. O papel do legislador democraticamente eleito, porém, é primordial na densificação da tutela constitucional do meio ambiente, o que atrai também a necessidade de ponderações entre a proteção dos bens ambientais e a efetivação de outros bens e direitos, podendo-se afirmar que não foi consagrada uma perspectiva "ecocêntrica" de tutela do meio ambiente.

Ao longo da História, a necessidade de assegurar a proteção da pessoa e de seus bens face a situações de risco originou diversas técnicas e mecanismos, como a securitária. $O$ desenvolvimento tecnológico e econômico confrontam a espécie humana com novos riscos, a exigir novo instrumental teórico de análise e gestão. O princípio da precaução desponta como mecanismo de orientação da conduta de agentes estatais e privados, sendo, porém, objeto de críticas quanto ao seu conteúdo e operatividade. Assim, o grau de certeza científica exigida para se adotar ou vedar a adoção de uma determinada medida, a consideração ou não de um balanço entre os custos e os prejuízos envolvidos e o grau de vinculatividade dos instrumentos normativos que o consagram mostram-se extremamente discutíveis.

Parece mais adequada a afirmação de que se deve adotar uma postura preventiva agravada, que inclui, dentre outras, as seguintes dimensões: adoção de deveres destinados a minimizar os perigos 
e mesmo os riscos, desde que estes se revistam de uma mínima probabilidade, deveres de aprofundar as pesquisas científicas, de divulgar informações, de cooperação, inclusive no plano internacional, de promoção da participação do público nos procedimentos decisórios, de realização de procedimentos de avaliação de impacto ambiental e de risco ambiental, de estabelecimento de cláusulas de revisão e de adaptação das decisões de acordo com os avanços da técnica e as pesquisas científicas. Tal ênfase no tocante ao aspecto de dever da proteção ambiental não sobrecarrega a atuação estatal. Ao contrário, parece facilitá-la, ao estabelecer obrigações mais precisas a cargo dos indivíduos e empresas, ensejando uma fiscalização e exigibilidade mais eficientes por parte do Estado. A fórmula do "direito ao ambiente", por outro lado, parece exercer uma função mais retórica por buscar sensibilizar pessoas e instituições para uma dimensão de corresponsabilidade em relação aos outros e às futuras gerações, ampliando a adesão às normas ambientais.

\section{Referências}

ALEXY, Robert, Teoría de los Derechos Fundamentales. Madri: Centro de Estudios Politicos y Constitucionales, 2001.

BECK, Ulrich. La Sociedad de Riesgo. Barcelona: Paidós, 1998.

BOBBIO, Norberto. A Era dos Direitos. Rio de Janeiro: Campus, 1992.

BOHANES, Jan. Risk Regulation in WTO Law: a Procedure Based Approach to the Precautionary Principle. Columbia Journal of Transnational Law, p. 323-389, v. 40, n. 2, 2002.

BRASIL. Supremo Tribunal Federal. Agravo Regimental no Agravo de Instrumento $n^{\circ}$ 781.547. Rel. Min. Luis Fux. Diário da Justiça Eletrônico, Brasília, 29 mar. 2012. Disponível em: <http://redir.stf.jus. $\mathrm{br} /$ paginadorpub/paginador.jsp?docTP=TP\&doclD=1863498>. Acesso em: 28 ago. 2016. 
BRASIL. Supremo Tribunal Federal. Arguição de Descumprimento de Preceito Fundamental $n^{\circ}$ 101. Rel. Min. Cármen Lúcia. Diário da Justiça Eletrônico, Brasília, 04 jun. 2012. Disponível em: <http://redir. stf.jus.br/paginadorpub/paginador.jsp?docTP=AC\&doclD=629955>. Acesso em: 28 ago. 2016.

CANOTILHO, J. J. Gomes. Direito constitucional e teoria da constituição. 7. ed. Coimbra: Almedina, 2003.

CANOTILHO, J. J. Gomes. O Direito ao Ambiente como Direito Subjectivo. In: CANOTILHO, José Joaquim Gomes. Estudos sobre direitos fundamentais. Coimbra: Coimbra Editora, 2004. p. 177-189.

CORDEIRO, António Menezes. Direito dos seguros. Coimbra: Almedina, 2013.

DI GIORGI, Raffaele. Direito, democracia e risco: vínculos com o futuro. Porto Alegre: Sérgio Antonio Fabris Editor, 1998.

ENTERRÍA, Eduardo García de; FERNÁNDEZ, Tomás-Ramón. Curso de derecho administrativo. Madri: Civitas, 2002. v. II.

GOMES, Carla Amado. As operações materiais administrativas e o direito do ambiente. Lisboa: Associação Académica da Faculdade de Direito de Lisboa, 1999.

GOMES, Carla Amado. Dar o duvidoso pelo (In)certo? Reflexões sobre o "Princípio da Precaução". In: GOMES, Carla Amado. Textos dispersos de direito do ambiente. Lisboa: Associação Académica da Faculdade de Direito de Lisboa, 2005. p. 141-174.

GOMES, Carla Amado. Risco tecnológico, comunicação do risco e direito a saber. In: GOMES, Carla Amado (Coord.). Direito(s) dos riscos tecnológicos. Lisboa: Associação Académica da Faculdade de Direito de Lisboa, 2014, p. 17-38.

GOMES, Carla Amado. Risco e modificação do acto autorizativo concretizador de deveres de protecção do ambiente. Coimbra: Coimbra Editora, 2007.

LEITE, José Rubens Morato; AYALA, Patryck de Araújo. Direito ambiental na sociedade de risco. Rio de Janeiro: Forense Universitária, 2004. 
LOUREIRO, João. Da sociedade técnica de massas à sociedade de risco: prevenção, precaução e tecnociência: algumas questões juspublicísticas. In: ALMEIDA, Aníbal [et al.]. Estudos em

homenagem ao Prof. Doutor Rogério Soares. Studia luridica 61, Ad honorem 1. Coimbra: Coimbra Editora, 2001. p. 797-891.

MACHADO, Paulo Affonso Leme. Direito ambiental brasileiro. São Paulo: Malheiros, 2004.

MARTINS, Ana Gouveia e Freitas. O princípio da precaução no direito do ambiente. Lisboa: Associação Académica da Faculdade de Direito de Lisboa, 2002.

MIRANDA, Jorge. Manual de Direito Constitucional. Coimbra: Coimbra Editora, 2000. t. IV.

NABAIS, José Casalta. 0 dever fundamental de pagar impostos. Coimbra: Almedina, 1998.

NOVAIS, Jorge Reis. As restrições aos direitos fundamentais não expressamente autorizadas pela constituição. Coimbra: Coimbra Editora, 2003.

PRÉVOST, Denise. Selected international developments regarding health and environmental regulation of relevance to the European Union. European Environmental Law Review, v. 13, n. 2, p. 38-60, fev. 2004

RIALS, Stéphane. La Déclaration des Droits de l'Homme et du Citoyen. Paris: Hachette, 1988.

RIBEIRO, Amadeu Carvalhaes. Direito de Seguros: resseguro, seguro direto e distribuição de serviços. São Paulo: Atlas, 2006.

SCHMIDT-AßMANN, Eberhard. Recenti sviluppi del diritto amministrativo generale in Germania. Diritto Pubblico, Pádua, v. 3, n. 1, p. 27-73, genn./apr. 1997.

SUNSTEIN, Cass. Para além do princípio da precaução. Interesse Público, Belo Horizonte, ano 8, n. 37, maio/jun. 2006. Disponível em: <http://bid.editoraforum.com.br/bid/PDI0006. aspx?pdiCntd=49179>. Acesso em: 13 dez. 2013. 
VAQUÉ, Luis Gonzáles, EHRING, Lothar ; JACQUET, Cyril. Le principe de précaution dans la législation communautaire et nationale relative à la protection de la santé. Révue du Marché Unique Européen, Local ? n. 1, p. 79-127, 1999.

Recebido em: 15/06/2015

Aprovado em: 25/08/2016 